\title{
EFFECT OF IRRADIATION TIME ON DEPTH OF CURE, WATER SORPTION AND SOLUBILITY OF TWO BULK FILL RESIN COMPOSITES
}

\author{
Maha E. Elkorashy*
}

\begin{abstract}
Objectives: To evaluate the effect of irradiation time on depth of cure, water sorption and solubility of two bulk fill resin composites.

Methods: A total of 40 resin composite cylinders were prepared ( $6 \mathrm{~mm} \mathrm{x} \mathrm{4mm)} \mathrm{and} \mathrm{divided}$ into 4 groups according the resin composite used; X-tra fil (VOCO) and Quixfil (DENTSPLY) and irradiation time; $10 \mathrm{~s}$ or 20s. Top and bottom hardness were measured using Vickers microhardness tester. Depth of cure was measured using bottom / top hardness ratio. For water sorption and solubility assessment, 40 disc shaped specimens $(15 \mathrm{~mm} \times 1 \mathrm{~mm})$ were prepared and tested according to the ISO 4049. Data were tabulated and statistically analyzed.
\end{abstract}

Results: No significant differences were recorded between X-tra fil and Quixfil regarding depth of cure and water sorption at both irradiation times. Water sorption significantly decreased at $20 \mathrm{~s}$ curing for both resin composites. At 10s irradiation time, X-tra fil recorded a significantly higher solubility (10.99 \pm 2.58$)$ than $20 \mathrm{~s}(6.57 \pm 1.78)$ and higher solubility than Quixfil $(5.79 \pm 2.62)$.

Conclusion: X-tra fil and Quixfil showed depth of cure within the acceptable threshold value. Both materials showed acceptable water sorption and solubility according to the ISO 4049 except $\mathrm{X}$-tra fil showed unacceptable solubility at 10s curing. Longer irradiation time greatly improved water sorption and solubility. Both bulk fill resin composites behave similarly at longer irradiation time.

KEY WORDS: Bulk fill resin composite, Depth of cure, Water sorption, Solubility, Irradiation time.

\section{INTRODUCTION}

Resin-based composites have been successfully used in dentistry for many years and widely replaced amalgam as a posterior restoration. The incremental technique has been recommended as a standard technique to reduce polymerization shrinkage, improve marginal adaptation and achieve reliable bond strength. ${ }^{(1,2)}$ However, restoration of posterior

\footnotetext{
* Lecturer, Operative Dentistry Department, Faculty of Dentistry, Fayoum University
} 
cavities with incremental technique, especially deep ones, implies the risk of incorporating air bubbles or contaminants between increments and is also time consuming. ${ }^{(3,4)}$ Bulk fill resin composites have been introduced to the market to be applied in $4 \mathrm{~mm}$ thickness increments without affecting polymerization shrinkage, cavity adaptation and degree of monomer conversion. ${ }^{(5)}$ Manufacturers promote light transmittance through the use of transparent fillers, highly reactive initiator systems and/or polymerization modulators to achieve a proper depth of cure up to $4 \mathrm{~mm}$ thickness increments. ${ }^{(4,6)}$

The depth of cure is the depth to which the light is able to harden the material. It has significant influence on both physical, mechanical as well as biological properties of restorations. ${ }^{(7)}$ Insufficient polymerization will result in unreacted monomers which would elute from the dental restoratives especially from the bottom surface of the restorations. These eluted substances have the potential to irritate soft tissues and pulp. ${ }^{(\mathbf{8}, \mathbf{9})}$ The degree to which resin composites are cured is proportional to the amount of light to which they are exposed. They polymerize to a certain depth which varies with the penetration of a light beam into the bulk material. ${ }^{(7)}$

The intensity of light is decreased as it passes through resin composite due to its absorption and scattering by the restorative material which attenuates its curing potential. ${ }^{(10)}$ The total energy supplied to resin composites is determined by the light intensity multiplied by irradiation time to obtain optimal degree of monomer to polymer conversion. Increasing photo-activation time increases the total amount of energy delivered to resin composite and it can compensate for the decreased light intensity. ${ }^{(11)}$

One of the major challenges facing dental restoratives is the moisture or the hydrolytic nature of the oral environment. The size of water molecules is less than $0.158 \mathrm{~nm}$ which is smaller than the inter- chain spaces of the resin matrices and hence, it can diffuse easily within these small spaces. ${ }^{(12)}$ The restorative materials respond to hydration through two different mechanisms: increase in the materials' weight due to water sorption and the second is losing weight as a result of leaching out of the soluble components. ${ }^{(13-15)}$

It has been reported that hygroscopic expansion resulting from water sorption might relieve some of the polymerization shrinkage stresses induced in resin composites and reduce interfacial gaps. (14,16) However, water sorption is a slow process when compared to polymerization shrinkage and stress development. ${ }^{(17)}$ Nevertheless, hygroscopic expansion can be greater than the induced shrinkage and thus can cause expansion stresses, which may induce micro-cracks or fracture of enamel due to the outward force against the cavity walls. ${ }^{(16)}$ Also, sorbed water may act as plasticizer resulting in deterioration of physical and mechanical properties of the restorative materials. ${ }^{(14)}$

Accordingly, the current study was conducted to investigate depth of cure, water sorption and solubility of two bulk fill resin composites cured for different irradiation times.

\section{MATERIALS AND METHODS:}

Two commercially available bulk fill resin composites were used in the study with shade A3 (table 1).

\section{Measurement of depth of cure}

A total of 40 cylindrical resin composite specimens were prepared, $6 \mathrm{~mm}$ in diameter and $4 \mathrm{~mm}$ in height, using a split Teflon mold. The samples were divided into 4 groups according to the type of bulk fill composite (X-tra fil or Quixfil) and irradiation time (10s or 20s). The resin composite was applied in the mold, covered with mylar strips and light cured using LED light curing unit with an intensity of $1200 \mathrm{~mW} / \mathrm{cm}^{2}$ (Elipar ${ }^{\mathrm{TM}} \mathrm{S} 10,3 \mathrm{M}$ ESPE, 
TABLE (1) The materials used in the study

\begin{tabular}{|c|c|c|c|c|}
\hline \multirow{2}{*}{ Product } & \multirow{2}{*}{ Manufacturer } & \multicolumn{2}{|r|}{ Composition } & \multirow{2}{*}{ Patch Number } \\
\hline & & Matrix & Fillers & \\
\hline X-tra fil & $\begin{array}{l}\text { VOCO, } \\
\text { Cuxhaven, } \\
\text { Germany }\end{array}$ & $\begin{array}{c}\text { Bis-GMA } \\
\text { UDMA } \\
\text { TEGDMA }\end{array}$ & $\begin{array}{l}\text { Barium-boron-alumino-silicate glass } \\
86 \% \text { by weight, }(70.1 \% \text { by volume }) \\
\text { Size }(0.05-10 \mu \mathrm{m})\end{array}$ & $888-658-2584$ \\
\hline Quixfil & $\begin{array}{l}\text { DENTSPLY, } \\
\text { Detry, } \\
\text { Germany }\end{array}$ & $\begin{array}{l}\text { Bis-EMA } \\
\text { UDMA } \\
\text { TEGDMA } \\
\text { TMPTMA } \\
\text { TCB }\end{array}$ & $\begin{array}{l}\text { Strontium aluminum sodium fluoride } \\
\text { phosphate silicate glass } \\
86 \% \text { by weight ( } 66 \% \text { by volume) } \\
\text { Size }(1-10 \mu \mathrm{m})\end{array}$ & $302-422-4511$ \\
\hline $\begin{array}{l}\text { Bis-GMA: } \\
\text { UDMA: Ur } \\
\text { TEGDMA: } \\
\text { Bis-EMA: } \\
\text { TMPTMA } \\
\text { TCB: Tetra }\end{array}$ & $\begin{array}{l}\text { phenol A diglycid } \\
\text { lane dimethacrylat } \\
\text { iethylene glycol d } \\
\text { phenol-A polyethy } \\
\text { rimethylolpropane } \\
\text { boxylic acid bishy }\end{array}$ & $\begin{array}{l}\text { lethacrylate } \\
\text { thacylate } \\
\text { e glycol dietl } \\
\text { nethacrylate } \\
\text { xyethyl meth }\end{array}$ & $\begin{array}{l}\text { dimethacrylate } \\
\text { rylate }\end{array}$ & \\
\hline
\end{tabular}

St. Paul, USA). Specimens were then stored dry in light proof labeled containers for $24 \mathrm{~h}$ before testing.

For microhardness testing, a Vickers Microhardness tester was used (Nexus $4000^{\mathrm{TM}}$, INNOVTEST Europe BV, Borgharenweg, Netherlands) with a load of $500 \mathrm{~g}$ and dwell time of $15 \mathrm{~s}$ under $20 \mathrm{X}$ magnification scale. Top and bottom surfaces were measured for each specimen. Three readings for each surface were taken and an average reading was calculated. Depth of cure for each sample was measured by using the ratio of bottom / top hardness. ${ }^{(18)}$

\section{Assessment of water sorption \& solubility}

A total of 40 specimens were prepared and tested according to the ISO 4049. Disc specimens were prepared using a split Teflon mold with dimensions of $15 \mathrm{~mm}$ diameter and $1 \pm 0.1 \mathrm{~mm}$ thickness. The samples were divided into 4 groups as previously mentioned. Resin composites were packed in the mold with slight overfilling, covered with polyester paper and gently pressed against a glass slide to extrude excess material. To ensure uniform curing, each disc specimen was divided into 4 quadrants by the presence of marks on the mold. Each quadrant was cured separately through the polyester paper for either $10 \mathrm{~s}$ or $20 \mathrm{~s}$ according to the experimental condition while the other 3 quadrants were covered with an opaque paper to avoid passage of the curing light (fig. 1).

The specimens were dried thoroughly at $37 \pm 1^{\circ} \mathrm{C}$ for $24 \mathrm{~h}$ in a desiccator containing dry anhydrous silica gel and then stored in another desiccator and kept at room temperature $(23 \pm 1)$ for one hour. The specimens were weighed after that with a digital balance with a precision of $0.0001 \mathrm{gm}$ (Sartorius AZ 214, Sartorius Mechatronics Corp, Bohemia, NY USA) with an accuracy of $\pm 0.1 \mathrm{mg}$. The specimens were weighed several times until a constant mass (m1) was obtained.

After recording $\mathrm{m} 1$, each disc specimen was immersed in distilled water individually in a tightly closed container at $37 \pm 1^{\circ} \mathrm{C}$ for 7 days period. After storage, the specimens were removed from water 


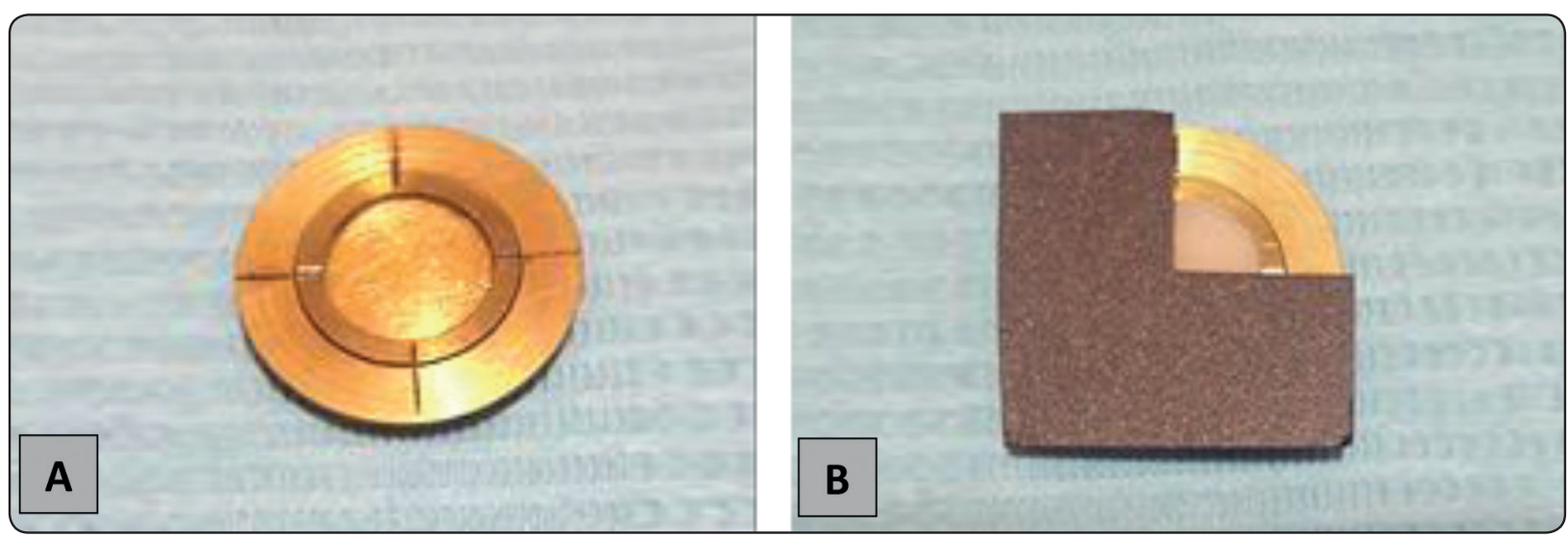

Fig. (1) An image showing the mold divided into 4 quadrants (A) and the opaque paper covering 3 quadrants of the specimen to ensure uniform curing (B).

and wiped with a dry clean towel, until they become free from visible moisture to record the mass (m2).

After this weighing, the specimens were dried again in the desiccators until reaching a constant mass using the same regimen described before to record the mass (m3). For each specimen, the diameter and the thickness were measured using a digital caliper (Mitutoyo digimatic caliper, Mitutoyo Corp, Kawosaki, Japan) with a precision $0.001 \mathrm{~mm}$ to calculate the volume $\mathrm{V}$ in $\mathrm{mm}^{3}$. The thickness was measured at the center and four equally spaced points on the circumference of each specimen to calculate its average thickness.

Water sorption (Wsp) in $\mu \mathrm{g} / \mathrm{mm}^{3}$ was then calculated for each specimen using the following equation: $\mathrm{Wsp}=\mathrm{M}_{2}-\mathrm{M}_{3} / \mathrm{V}$

Solubility (Wsl) in $\mu \mathrm{g} / \mathrm{mm}^{3}$ for each specimen was calculated using the following equation: Wsl= $\mathrm{M}_{1}-\mathrm{M}_{3} / \mathrm{V}$

Where $\mathrm{M}_{1}$ : is the conditioned mass, in micrograms, prior to immersion in water. $M_{2}$ : is the mass of the specimen, in micrograms, after immersion in water for 7days. $\mathrm{M}_{3}$ : is the reconditioned mass of the specimens, in micrograms. V: is the volume of the specimens in $\mathrm{mm}^{3}$.

\section{Statistical analysis}

Data were presented as mean and standard deviation values. Two-way ANOVA test was used to compare between groups followed by Tukey post hock test when ANOVA test revealed significant difference.

\section{RESULTS}

\section{Results of depth of cure}

All tested groups showed depth of cure higher than $80 \%$ as shown in figure 2. Depth of cure results revealed no significant difference between $\mathrm{X}$-tra fil and Quixfil or between 10s and 20s irradiation times in any of the tested groups.

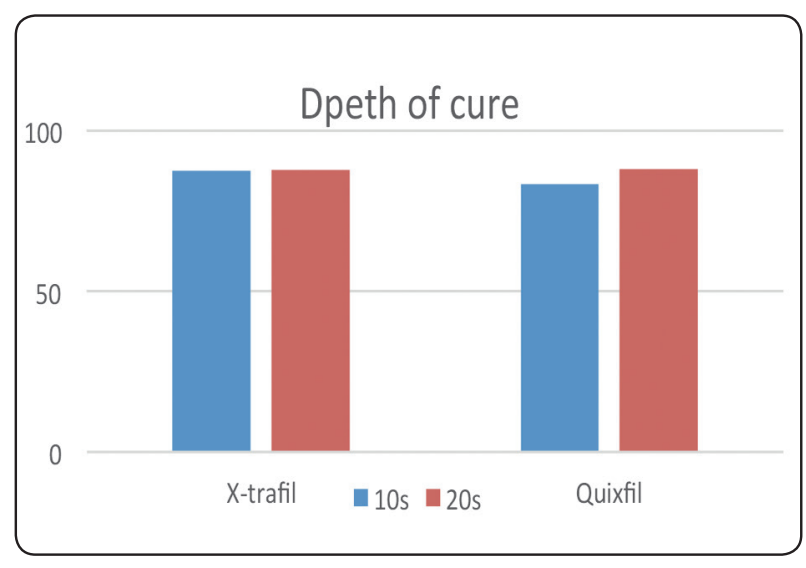

Fig. (2) A bar chart showing depth of cure of bulk fill resin composites at different irradiation times 


\section{Results of water sorption and solubility}

TABLE (2) Mean values and standard deviations (SD) of water sorption of bulk fill resin composites at different irradiation times:

\begin{tabular}{|c|c|c|c|}
\hline & 10s & 20s & P-value \\
\hline X-tra fil & $23.72 \pm 2.06$ & $20.82 \pm 1.85$ & $0.042^{*}$ \\
\hline Quixfil & $24.04 \pm 2.34$ & $21.14 \pm 2$ & $0.042^{*}$ \\
\hline P-value & 0.813 & 0.813 & \\
\hline$P \leq 0.05$ & & & \\
\hline
\end{tabular}

Water sorption results revealed no significant differences between X-tra fil and Quixfil resin composites at either 10 s or 20 s irradiation times. Irradiation time significantly affected water sorption results as 20 s showed significantly lower water sorption values than $10 \mathrm{~s}$ in $\mathrm{X}$-tra fil resin composite with values of $(20.82 \pm 1.85)$ and $(23.72 \pm 2.06)$ and Quixfil resin composite with values of $(21.14 \pm 2)$ and (24.04 \pm 2.34$)$ respectively (table 2)

TABLE (3) Mean values and standard deviations (SD) of solubility of bulk fill resin composites at different irradiation times:

\begin{tabular}{|c|c|c|c|}
\hline & 10s & 20s & P-value \\
\hline X-tra fil & $10.99 \pm 2.58$ & $6.57 \pm 1.78$ & $0.006^{*}$ \\
\hline Quixfil & $5.79 \pm 2.62$ & $3.86 \pm 1.63$ & 0.185 \\
\hline P-value & $0.002^{*}$ & 0.069 & \\
\hline \multicolumn{4}{|c|}{$P \leq 0.05$} \\
\hline
\end{tabular}

Regarding solubility results, table 3 showed that $\mathrm{X}$-tra fil recorded a higher solubility values at $10 \mathrm{~s}$ $(10.99 \pm 2.58)$ than $20 \mathrm{~s}(6.57 \pm 1.78)$ with significant difference while, Quixfil showed no significant difference between both irradiation times. X-tra fil composite revealed a significantly higher solubility than Quixfil composite at 10s irradiation time with mean values of $(10.99 \pm 2.58)$ and $(5.79 \pm 2.62)$ respectively.

\section{DISCUSSION}

The bulk filling technique has become mandatory in the daily dental practice specially in restoring posterior cavities. It saves chair side time and makes the restorative procedure easier and more comfortable to the patient, ${ }^{(1)}$ but concerns about inadequate polymerization with its consequences still evolved. Many factors influence the polymerization kinetics of resin-based composite materials and affect their behavior such as irradiation time, light intensity (19) and chemical characteristics of monomers as the types of co-monomers, molar mass and amount of hydrogen bonding. ${ }^{(20)}$

The manufacturers reported that curing for 10 s using light curing units with an intensity of $800 \mathrm{~mW} / \mathrm{cm}^{2}$ or more is sufficient for adequate polymerization of both resin composites used in the current study. However, numerous in vitro studies have recommended a minimum of 20 s curing time to properly polymerize resin composites to deeper layers. These studies found no significant differences between 20 s and 40 s curing times. ${ }^{(5,21,22)}$ For this reason, irradiation of resin composite for 10 s and 20s was selected for the current study.

The microhardness values obtained were used to calculate a bottom/top hardness ratio as a reflection of the depth of cure. In the current study, all tested groups represented a hardness ratio exceeds $80 \%$ which is considered as a minimum acceptable threshold value. ${ }^{(3)}$ Depth of cure of light-curing resin composites is a function of filler size and load, monomer composition, shade and translucency of the material, intensity of the light source, irradiation time and initiator concentration. ${ }^{(4)}$

In the current study, results of depth of cure revealed no significant differences between X-tra fil and Quixfil resin composites at any of the 
irradiation times. This finding might be attributed to the composition of both resin composites as X-tra fil and Quixfil contain the same filler loading, $86 \%$ by weight, and the same particle size up to $10 \mu \mathrm{m}$. Subsequently, the same surface area between fillers and organic matrix and the same light scattering potential. ${ }^{(4)}$ The amount of scattered and absorbed light affects the amount of light transmitted through a composite material. ${ }^{(5,23)}$ Also, the monomer composition might play a role in this finding as Sideridou et al, ${ }^{(24)}$ reported that the degree of conversion of Bis-EMA monomer is higher than that of Bis-GMA. The degree of monomer conversion is attributed to the difference in monomer viscosity ${ }^{(25)}$ where the viscosity of Bis-EMA is lower than the viscosity Bis-GMA.(5) Viscosity of monomers, is as determined by their chemical characteristics, was found to influence the polymerization rate due to its effect on the mobility of the monomers and free radicals. ${ }^{(26,27)}$ Bis-EMA is a monomer which is structurally similar to Bis-GMA, but without the two pendant hydroxyl groups, which participate in hydrogen bonding and are responsible for the extremely high viscosity of Bis-GMA. ${ }^{(20,25)}$ Viscosity is inversely related to the degree of conversion but to a certain limit where the decrease in viscosity negatively affects degree of conversion as a result of increased diffusion-controlled termination. ${ }^{(20)}$

In addition, optical characteristics of resin composites are of major importance in affecting light transmission and consequently degree of monomer conversion, mechanical characteristics and clinical performance. ${ }^{(28)}$ Tarle et al, ${ }^{(4)}$ reported that the translucency of X-tra fil is $23 \%$ and that of Quixfil is $17 \%$ based on the data supplied by the manufacturers. The depth of cure of resin composites could be improved by increasing the material's translucency. ${ }^{(23)}$ Therefore, the higher degree of conversion of Bis-EMA, which is the main monomer of Quixfil in comparison to the higher translucency percentage of the X-tra fil in addition to the same filler size and load of both resin composites might explain the insignificant depth of cure.

Dental restorative materials are in continuous contact with fluids and saliva in the patient's mouth. Water sorption by composite materials is a diffusion-controlled process, and the water uptake occurs largely in the resin matrix. The water uptake by the polymer matrix could cause fillermatrix debonding or even hydrolytic degradation causing reduction in mechanical properties of resin composites. The hydrolytic degradation is a result of either the breaking of chemical bonds in the resin or softening through the plasticizing action of water. When resin samples are immersed in water, some of the components, such as unreacted monomers or fillers, dissolve and are leached out of the samples. This results in loss of weight and can be measured as solubility or leaching. ${ }^{\text {(13) }}$

The ISO 4049 reported that resin-based materials must have water sorption values equal or lower than $40 \mu \mathrm{g} / \mathrm{mm}^{3}$ and solubility values equal or lower than $7.5 \mu \mathrm{g} / \mathrm{mm}^{3}$ for specimens of $15 \mathrm{~mm}$ diameter and $1 \mathrm{~mm}$ thickness. ${ }^{(2)}$ Water sorption and solubility values above these critical points have an adverse effect on the physical and mechanical properties of these materials, such as strength, surface hardness, wear resistance and color stability and thus on their clinical behavior and biocompatibility. ${ }^{(30,31)}$

The water sorption results of the tested groups in the current study ranged from 20.82 to 24.04 $\mu \mathrm{g} / \mathrm{mm}^{3}$, which were lower than the maximum water sorption value accepted by the ISO 4049 . Regarding solubility, all tested groups showed acceptable solubility results except the X-tra fil at 10s irradiation time, which revealed a clinically unacceptable solubility $(10.99 \pm 2.58)$.

The findings of the present study reported great influence of the irradiation time on water sorption, as 20 s curing resulted in significantly lower values than 10s in both resin composites. According to Yap et al ${ }^{\text {(32) }}$ the cross-link density of a polymer 
system plays an important role in the physical and mechanical properties of the final material. Crosslinking provides a large number of bridges between linear macromolecules to form a three-dimensional network which diminishes water sorption and solubility and reduces the permeability of the polymers. ${ }^{(33,34)}$ Increased cross linking might be an explanation for the improved water sorption results at 20 s irradiation time.

Moreover, water sorption results reported insignificant difference between X-tra fil and Quixfil at any of the irradiation times. Water sorption and solubility of dental resin composites are influenced by several factors as matrix composition, filler type and size and degree of conversion. ${ }^{(34,35)}$ This finding might be attributed to the similar degree of monomer to polymer conversion of both tested resin composites as discussed previously in the depth of cure results. Tolendano et al, ${ }^{(13)}$ reported that the increased weight of the specimens does not represent the water gain only, but rather the difference between the amount of water gain and the dissolution of leachable molecules. Chemistry of the monomers is the key of the hydrophilic nature of the polymer ${ }^{(36,37)}$ and this hydrophilicity determines the amount of water that composite resins can absorb. ${ }^{(37)}$ Bis-GMA is said to be more hydrophilic than Bis-EMA and consequently runs a higher risk of water uptake and degradation. ${ }^{(5)}$ This might be another explanation of the insignificant water sorption results of both resin composites as the X-tra fil resin composite absorbed more water and leached out more material due to its Bis-GMA content resulting in the same net weight gain as the Quixfil resin composite.

Regarding solubility, X-tra fil resin composite showed higher solubility results than Quixfil at 10s curing time (Table 3 ). This could be explained by the higher hydrophilicity of the Bis-GMA monomer in comparison to Bis-EMA ${ }^{(5)}$ in combination to the decreased cross linking density achieved with 10 s curing. At 20s curing, X-tra fil showed improved solubility which may be due to the higher degree of cross linking of monomers and higher degree of entanglement between linear chains as mentioned before. Da Silva et $a l,{ }^{(36)}$ showed a correlation between solubility and degree of conversion in nanofilled and hybrid composites. The water sorption and solubility results of the current study was in accordance to De Castro et al, ${ }^{(38)}$ who revealed improved performance of water sorption and solubility of tested composites cured for longer irradiation times.

To summarize, the prolonged irradiation time showed improved water sorption and solubility of the tested resin composites but no effect regarding their depth of cure. Quixfil showed better solubility with short irradiation times but with longer irradiation, both materials performed within the clinically acceptable threshold values.

\section{CONCLUSIONS:}

Within the limitation of the current study, the following could be concluded:

1- X-tra fil and Quixfil showed acceptable depth of cure and water sorption but X-tra fil resin composite showed unacceptable solubility at 10s irradiation time.

2- Longer irradiation time did not improve depth of cure of both resin composites but greatly improved water sorption and solubility.

3- Both bulk fill resin composites behave similarly at longer irradiation time despite the difference in their chemical composition.

\section{REFERENCES}

1. El-Safty S, Silikas N, Watts DS. Creep deformation of restorative resin-composites intended for bulk-fill placement. Dental Materials; 28: 928-935, 2012.

2. Ende AV, De Munck J, Van Landuyt KL, Poitevin A, Peumans M, Van Meerbeek B. Bulk-filling of high C-factor 
posterior cavities: effect on adhesion to cavity-bottom dentin. Dental Materials; 29: 269-277, 2013.

3. Flury S, Hayoz S, Peutzfeldt A, Hüsler J, Lussi A. Depth of cure of resin composites: Is the ISO 4049 method suitable for bulk fill materials? Dental Materials; 28: 521-528, 2012.

4. Tarle Z, Attin T, Marovic D, Andermatt L, Ristic M, Tauböck TT. Influence of irradiation time on subsurface degree of conversion and microhardness of high-viscosity bulk-fill resin composites Clinical Oral Investigations; 19: 831-840, 2015.

5. Czasch P, Ilie N. In vitro comparison of mechanical properties and degree of cure of bulk fill composites. Clinical Oral Investigations; 17(1): 227-235, 2013.

6. Finan L, Palin WM, Moskwa N, McGinley EL, Fleming GJP. The influence of irradiation potential on the degree of conversion and mechanical properties of two bulk-fill flowable RBC base materials. Dental materials; 29(8): 906-912, 2013.

7. El-Nawawy M, Koraitim L, Abouelatta O, Hegazi H. Depth of cure and microhardness of nanofilled, packable and hybrid dental composite resins. American Journal of Biomedical Engineering; 2(6): 241-250, 2012.

8. Sideridou ID, Achilias DS. Elution study of unreacted BisGMA, TEGDMA, UDMA, and Bis-EMA from light-cured dental resins and resin composites using HPLC. Journal of Biomedical Materials Research. Part B, Applied Biomaterials; 74(1): 617-626, 2005.

9. Lee SY, Huang HM, Lin CY, Shih YH. Leached components rom dental composites in oral simulating fluids and the resultant composite strengths. Journal of Oral Rehabilitation; 25(8): 575-588, 1998.

10. Ceballos L, Fuentes MV, Tafalla H, Martínez A, Flores J, Rodríguez J. Curing effectiveness of resin composites at different exposure times using LED and halogen units. Journal of Clinical and Experimental Dentistry; 1(1): e8e13, 2009.

11. Discacciati JAC, Neves AD, Oréfice RL, Pimenta FJGS, Sander HH. Effect of light intensity and irradiation time on the polymerization process of a dental composite resin. Materials Research; 7(2): 313-318, 2004.

12. Tamai Y, Tanaka H, Nakanishi K. Molecular simulation of permeation of small penetrants through membranes 2.Solubilities. Macromolecules; 28(7): 2544-2554, 1995.
13. Toledano M, Osorio R, Osorio E, Fuentes V, Prati C, García-Godoy F. Sorption and solubility of resin-based restorative dental materials. Journal of Dentistry; 31(1): 43-50, 2003.

14. Al Qahtani MQ, Binsufayyan SS, Al shaibani HA, Lamri HG. Effect of immersion media on sorption and solubility of different tooth colored-restoratives. Pakistan Oral \& Dental Journal; 32(2): 304-310, 2012.

15. El-Bader RM, Ziadan KM, Al-Ajely MS. Water adsorption characteristics of new dental composites. International Journal of Medical Research and Health Science; 4(2): 281-286, 2015.

16. Reddy AM, Kumar D, Shivanna V. Thermal cyclic changes on water sorption and solubility of composite restoratives - An in-vitro study. Journal of Conservative Dentistry; 9(2): 63-71, 2006.

17. Sakaguchi RL, Powers JM. Craig's restorative dental materials: Restorative materials-composites and polymers. $13^{\text {th }}$ edition, Elsevier Mosby Philadelphia, 177, 2012.

18. Moore BK, Platt JA, Borges G, Chu TM, Katsilieri I. Depth of cure of dental resin composites: ISO 4049 depth and microhardness of types of materials and shades. Operative Dentistry; 33: 408-412, 2008.

19. Emami N, Soderholm KJ. How light irradiance and curing time affect monomer conversion in light-cured resin composites. European Journal of Oral Science; 111: 536-542, 2003.

20. Gonçalves F, Kawano Y, Pfeifer C, Stansbury JW, Braga RR. Influence of BisGMA, TEGDMA, and BisEMA contents on viscosity, conversion, and flexural strength of experimental resins and composites. European Journal of Oral Science; 117: 442-446, 2009.

21. Polydorou O, Trittler R, Hellwig E, Kummerer K. Elution of monomers from two conventional dental composite materials. Dental Materials; 23: 1535-1541, 2007.

22. Frauscher KE, Ilie N. Degree of conversion of nano-hybrid resin-based composites with novel and conventional matrix formulation. Clinical Oral Investigations; 17(2): 635642, 2013.

23. Bucuta S, Ilie N. Light transmittance and micro-mechanical properties of bulk fill vs. conventional resin based composites. Clinical Oral Investigations; 18(8); 1991-2000, 2014.

24. Sideridou I, Tserki V, Papanastasiou G. Effect of chemical structure on degree of conversion in light-cured dimeth- 
acrylate based dental resins. Biomaterials; 23: 1819-829, 2002.

25. Cornelio RB, Wikant A, Mjosund H, Kopperud HM, Haasum J, Gedde UW, Örtengren UT. The influence of BisEMA vs Bis-GMA on the degree of conversion and water susceptibility of experimental composite materials. Acta Odontologica Scandinavica; 72(6): 440-447, 2014.

26. Stansbury JW, Dickens SH. Determination of double bond conversion in dental resins by near infrared spectroscopy. Dental Materials; 17: 71-79, 2001.

27. Dickens S, Stansbury JW, Choi KM, Floyd CJE. Photopolymerization kinetics of methacrylate dental resins. Macromolecules; 36: 6043-6053, 2003.

28. Howard B, Wilson ND, Newman SM, Pfeifer CS, Stansbury JW. Relationships between conversion, temperature and optical properties during composite photopolymerization. Acta Biomaterialia; 6: 2053-2059, 2010.

29. International Standardization Organization. ISO4049: Dentistry polymer - based filling, restorative and luting materials, 2000 .

30. Janda R, Roulet JF, Latta M, Ruttermann S. Water sorption and solubility of contemporary resin-based filling materials. Journal of Biomedical Materials Research. Part B, Applied Biomaterials; 82: 545-551, 2007.

31. Archegas LR, Caldas DB, Rached RN, Vieira S, Souza EM. Sorption and solubility of composites cured with quartz tungsten halogen and light emitting diode lightcuring units. Journal of Contemporary Dental Practice; 9: 73-80, 2008.
32. Yap AU, Soh MS, Han TT, Siow KS. Influence of curing lights and modes on cross-link density of dental composites. Operative Dentistry; 29: 410-415, 2003.

33. Ferracane JL. Hygroscopic and hydrolytic effects in dental polymer networks. Dental Materials; 22: 211-222, 2006.

34. Sideridou I, Tserki V, Papanastasiou G. Study of water sorption, solubility and modulus of elasticity of light-cured dimethacrylate-based dental resins. Biomaterials; 24(4): 655-665, 2003.

35. Mortier E, Jager S, Alain D. Influence of filler amount on water sorption and solubility of three experimental flowable composite resins. Journal of Materials Science and Engineering with Advanced Technology; 7(1): 35-48, 2013.

36. Da Silva EM, Almeida GS, Poskus LT, Guimarães JGA. Relationship between the degree of conversion, solubility and salivary sorption of a hybrid and a nanofilled resin composite: influence of the light activation mode. Journal of Applied Oral Science; 16(2): 161-166, 2008.

37. Berger SB, Palialol ARM, Cavalli V, Giannini M. Characterization of water sorption, solubility and filler particles of light-cured composite resins. Brazilian Dental Journal; 20(4): 314-318, 2009.

38. De Castro FLA, Campos BB, Bruno KF, Reges RV. Temperature and curing time affect composite sorption and solubility. Journal of Applied Oral Science; 21(2): 157162, 2013. 